\title{
A (IN)SUSTENTABILIDADE DO DISCURSO DA EDUCAÇÃO PARA O DESENVOLVIMENTO SUSTENTÁVEL DO BANCO MUNDIAL
}

\section{Luciano Accioly Lemos Moreira}

\section{RESUMO}

A partir da década de 70 do século XX o capital adentra numa crise estrutural, causando com isso, efeitos danosos a vida humana de maneira continuada e rastejante. Devido aos danos econômicos, políticos e ecológicos de um modo de produção destrutivo de nossa época, o capital tenta dar resposta a sua crise estrutural. Tem-se em vários setores da sociedade e mais precisamente na educação, o surgimento do discurso da sustentabilidade como possibilidade na resolução dos conflitos de nossa época. Proporemos-nos analisar o discurso sobre a educação para o desenvolvimento sustentável contidos nos projetos do Banco Mundial e da ONU a partir da década de 90 do século XX. Procuraremos demonstrar as permanências e rupturas desse dizer, as possibilidades e limites desse novo projeto desenvolvimentista na reprodução da sociabilidade capitalista. Acreditamos que ao explicitarmos a voz ideológica do capital a sua crise, demonstrando o seu funcionamento, sua operacionalidade e limites, estaremos também, contribuindo para ecoar o que se quer silenciar, ou seja, a insustentabilidade de um sistema que refrea o livre desenvolvimento dos indivíduos. Com isso, a sustentabilidade da humanidade terá como possibilidade efetiva apenas quando o controle social da produção, da circulação e do consumo estiverem sob o controle consciente dos trabalhadores associados, ou seja, numa sociedade para além da escravidão assalariada do capital, numa sociabilidade comunista.

\section{PALAVRAS-CHAVE}

Educação; Sustentabilidade; Capitalismo

\section{THE (IN)SUSTENTABILIDADE OF THE SPEECH OF THE EDUCATION FOR THE SUSTAINABLE DEVELOPMENT OF THE WORLD BANK}

\begin{abstract}
From the decade of 70 of century XX the capital adentra in a structural crisis, causing with this, harmful effect the life human being in continued and rastejante way. Had to the economic damages, ecological politicians and in a destructive way of production of our time, the capital tries to give to reply its structural crisis. It is had more necessarily in some sectors of the society and in the education, the sprouting of the speech of the sustentabilidade as possibility in the resolution of the conflicts of our time. We will consider ourselves to analyze the speech on the education for the sustainable development contained in the projects of the World Bank and the ONU from the decade of 90 of century XX. We will look for to demonstrate to the permanências and ruptures of this to say, the possibilities and limits of this new desenvolvimentista project in the reproduction of the capitalist sociability. We believe that when explicitarmos the ideological voice of the capital its crisis, demonstrating its functioning, its operationalization and limits, we will be also, contributing to echo what if it wants to silence, or either, the insustentabilidade of a refrea system that the free development of the individuals. With this, the sustentabilidade of the humanity will have as possibility only accomplishes when the social control of the production, the circulation and the consumption will be under the conscientious control of the workers associates, or either, in a society for beyond the wage-earning slavery of the capital, in a communist sociability.
\end{abstract}

\section{KEYWORDS}

Education; Sustentabilidade; Capitalism 
Neste artigo procuraremos refletir sobre a proposta de uma educação para o desenvolvimento sustentável, defendida pela Organização das Nações Unidas (ONU). Ao dialogar com tal projeto, tentaremos explicitar os motivos e as pretensões desse programa para a humanidade. Antes, porém, apresentaremos uma breve explicação do que vem a ser tal órgão internacional, sua função e operacionalidade para a dinâmica do capital.

A Organização das Nações Unidas (ONU) é uma instituição internacional composta por 192 Estados soberanos. Sua fundação se deu após a Segunda Guerra Mundial (1945) e tem, conforme seu programa oficial, o objetivo de promover a paz, a segurança e o progresso entre os povos. Seu programa está contido na carta da ONU, na qual a China, os Estados, a França, o Reino Unido e a ex-União Soviética, estabeleceram os direitos e deveres dos membros da comunidade internacional que participaram de suas assembléias.

A ONU é formada por seis órgãos e tem sua sede situada na cidade de Nova York nos Estados Unidos. É, ainda, composta por organismos especializados em vários setores estratégicos. Desse modo, está diretamente ligada à Organização Mundial de Saúde (OMS), à Organização Internacional do Trabalho (OIT), ao Banco Mundial, ao Fundi Monetário Internacional (FMI) e à Organização das Nações Unidas para a Educação, Ciência e Cultura (UNESCO), entre outros. Estes órgãos internacionais, em conjunto, formam o Sistema das Nações Unidas.

O Brasil mantém relação e também representação com o Sistema das Nações Unidas, através da implantação de projetos em vários setores sociais, políticos, educacionais, culturais e econômicos, assim como, através da obtenção de empréstimos e convênios com órgãos das Nações Unidas, voltados ao interesses do capital internacional e local.

Em dezembro de 2002, a Assembléia Geral das Nações Unidas aprovou a Resolução n. ${ }^{0}$ 7/254, a qual determina que a partir de 2005 tivesse início a Década da Educação para o Desenvolvimento Sustentável (DEDS). A UNESCO consta como órgão responsável pela implantação dos projetos educacionais, científicos e culturais elaborados pela ONU nos países integrantes deste projeto.

O plano elaborado por esse órgão internacional para o Desenvolvimento Sustentável fornece as orientações e conselhos para os países envolvidos, demonstrando os passos que 
devem ser dados para desenvolverem suas economias sem que danifiquem a vida humana e a natureza.

Conforme o documento final da ONU, para a realização de uma educação voltada ao desenvolvimento sustentável (2005, p.28), “os padrões de produção e consumo como evidenciados nas sociedades industrializadas não poderiam ser mantidos, levando em consideração os recursos do planeta”. O desenvolvimento sustentável se configura, portanto, numa tentativa de implementação de um modelo produtivo capitalista que não coloque em risco a própria existência da humanidade. Assim, do ponto de vista do Sistema das Organizações das Nações Unidas, o sistema produtivo capitalista a partir do final do século XX, e início do século XXI, mostra sinais de destruição e de ameaça à continuidade da vida humana. Esse discurso torna-se evidente quando o projeto afirma que:

Poucos objetivos são mais urgentes e críticos para o futuro da humanidade do que
assegurar a melhoria constante da qualidade de vida para esta e para as futuras
gerações, o respeito a nosso patrimônio comum - o planeta em que vivemos. Como
pessoas, procuramos mudanças positivas para nós mesmos, para nossos filhos e
netos, devemos fazer isto respeitando o direito de todos de fazer o mesmo. Para isso,
devemos aprender constantemente sobre nós mesmos, nosso potencial, nossas
limitações, nossos relacionamentos, nossa sociedade, nosso meio ambiente, nosso
mundo. A educação para o desenvolvimento sustentável é um esforço vital e eterno
que desafia indivíduos, instituições e sociedades a olhar para o dia de amanhã como
um dia que pertence a todos nós ou não pertencerá a ninguém. (UNESCO, 2005,
p.25).

Confirma-se, portanto, que há na atualidade problemas na dinâmica do sistema capitalista em continuar o seu funcionamento. Dessa forma, ao enunciar que o "esforço" de todos nós na tentativa de amenização das dificuldades em que estamos passando se tornou "vital e eterno”, demonstra-nos a emergencialidade e severidade de tal crise. Assim, o termo “vital e eterno” que pode ser parafraseado por “essencial e infindável” respectivamente, explicita-nos que tanto o problema como as soluções, do ponto de vista da ONU, não têm uma resolução definitiva, mas apenas uma contínua preocupação e prevenção em relação à sobrevivência do homem e da vida.

Partindo-se desse pressuposto, o único horizonte possível para a humanidade é a amenização dos efeitos danosos provenientes das relações excessivas entre os homens e dos homens com a natureza. Com isso, conforme esse corpo legal, a natureza humana é propensa a excessos egoístas e individualistas, restando-nos a assimilação de valores éticos/morais que se coloquem contrários a essa ordem. 


\section{DESENVOLVIMENTO SUSTENTÁVEL: UM BREVE HISTÓRICO DESSE NOVO PROJETO IDEOLÓGICO DO CAPITAL}

De acordo com a ONU, o conceito de desenvolvimento sustentável tem sua gênese ainda na década de 70 do século passado. Com isso, em 1972, na cidade de Estocolmo, as Nações Unidas elaboraram sua primeira conferência para discutir o projeto de sustentabilidade para a humanidade.

Inicialmente, a preocupação do projeto centrava-se em relação a proteção dos recursos naturais, já que esses mostravam há muito tempo sinais de esgotamento em vários lugares do mundo. Posteriormente, o conceito e o próprio projeto de sustentabilidade ganhou, por parte do mesmo órgão idealizador, uma ampliação, visto que em 1987, uma outra comissão da ONU, ligada ao Meio ambiente e Desenvolvimento, publica uma obra intitulada: Nosso Futuro Comum. Nessa obra, o conceito de sustentabilidade não se restringe apenas a uma ação para o melhor uso dos bens naturais, mas também, refere-se ao desenvolvimento de um outro padrão produtivo, político e cultural, que por intermédio da educação, deverá ser incutido nos indivíduos. E esses sujeitos, assim educados, agirão sustentavelmente, tanto em seu espaço singular (comunidade, ONG, instituições locias, etc.), como também, em um nível mais amplo (órgãos internacionais, governos, empresas) em prol de um fim em comum.

De acordo com o referido documento, desenvolvimento sustentável conceitualmente quer dizer: "o desenvolvimento que satisfaz às necessidades do presente sem comprometer a capacidade das futuras gerações de satisfazer suas próprias necessidades” (UNESCO, 2005, p.37). Essa definição explicita ainda que enquanto o desenvolvimento for "essencial para satisfazer às necessidades humanas e melhorar a qualidade de vida, ele deve acontecer de tal maneira que não coloque em perigo a capacidade do meio ambiente natural em satisfazer as necessidades presentes e futuras” (UNESCO, 2005, p.37). Temos nessa citação a compreensão por parte desse projeto, que “desenvolvimento”, “necessidade humana” e “qualidade de vida”, estão pelo menos no modelo atual, representando existências opositoras em relação aos recursos naturais necessários às vidas presentes e futuras, ou seja, desenvolver e destruir são fases da mesma moeda.

Neste momento, podemos suscitar que há na essência da socialidade humana, conforme a ONU, um imperativo individual e social voltado para o crescimento acumulativo e expansivo do mercado capitalista, pois é da essência humana a propensão à luta por uma 
melhor qualidade de vida, só que contraditoriamente, essa dinâmica deve ser controlada, refreada, ou melhor, sustentável em vista de se tornar viável.

A definição de sustentabilidade é mais uma vez complementada em 1991 nos seguintes termos: para ocorrer o desenvolvimento sustentável é imprescindível "melhorar a qualidade da vida humana respeitando a capacidade do ecossistema” (UNESCO, 2005, p.36). Nessa rearrumação conceitual, a ONU afirma que é possível instaurar um outro modelo desenvolvimentista, que alie qualidade de vida e proteção ambiental. Esse padrão produtivo tornaria sustentável o sistema do capital, propiciando a regeneração de todo o ecossistema.

Na Cúpula de Joanesburgo, em 2002, a ONU amplia outra vez o mesmo conceito e propõe, numa assembléia geral, que o período de 2005 a 2015 seria denominado da Década da Educação para o Desenvolvimento Sustentável.

O projeto do Desenvolvimento Sustentável surge, desta maneira, como uma resposta ao padrão produtivo e consumista de um projeto desenvolvimentista que entra em crise. Referindo-se a esse modelo de desenvolvimento, a Organização das Nações Unidas (UNESCO, 2005) nos esclarece que:

\begin{abstract}
Os padrões de produção e consumo como evidenciados nas sociedades industrializadas não poderiam ser mantidos, levando-se em consideração os recursos do planeta. Assim como não se poderia impor um modelo de desenvolvimento às nações, supondo o tipo de consumo praticado pelos países industrializados. Embora o crescimento da consciência tenha tido um impacto sobre os sistemas de produção, mudando o estilo de vida, particularmente nos países industrializados, ela também foi direcionada para padrões incompatíveis com a sustentabilidade. Em termos gerais, enquanto a poluição provocada pela produção no mundo industrializado, a carga ambiental derivada do consumo tem crescido inexoravelmente. Cada vez mais é evidente que muitas questões sociais, econômicas e ambientais estão relacionadas entre si, como, por exemplo, pobreza, distribuição desigual de recursos, crescimento demográfico, migração, desnutrição, saúde e HIV/Aids, mudanças climáticas, fornecimento de energia, ecossistemas, diversidade biológica, recursos hídricos, segurança alimentar e toxinas prejudiciais ao meio ambiente. (UNESCO, 2005, p.28).
\end{abstract}

O padrão produtivo e consumista dos países industrializados não pode ser mantido, nem tampouco estendido aos países em desenvolvimento e/ou pobres. Parece-nos, preliminarmente, que de acordo com a ONU, encontramo-nos num beco sem saída, pois os países que já cresceram e, portanto, encontram-se do ponto de vista do sistema do capital num lugar economicamente privilegiado, deve repensar sua produção de maneira sustentável. Por outro lado, os países pobres e em vias de desenvolvimento estão impedidos dado à destruição desse modo de produção, de alcançarem os patamares de crescimento dos países avançados. 
Assim, podemos inferir que o tempo para crescer, ampliar e alargar-se já passou, resta-nos especular o que restou para os países pobres e em desenvolvimento. Num quadro explicativo contido no projeto para o desenvolvimento defini-se tal questão:

O crescimento econômico é o maior componente do desenvolvimento. Na verdade, o crescimento econômico, até recentemente foi visto por alguns como o meio e o objetivo do desenvolvimento. Com o crescimento da economia, intensificaram-se as pressões sobre o sistema e recursos naturais da Terra. Desse modo, por exemplo, de 1950 até 1997:

- o uso da madeira para construção triplicou;

- o uso do papel cresceu seis vezes mais;

- a pescaria quase quintuplicou;

- o consumo de grãos triplicou;

- o combustível fóssil quase quadruplicou, e

- os poluentes do ar e da água multiplicaram-se várias vezes.

A triste realidade é que a economia continua a crescer, mas o ecossistema do qual o crescimento econômico depende não se expande, criando cada vez mais uma relação sempre mais tensa. (UNESCO, 2005, p.29).

A ONU, ao pronunciar-se sobre “crescimento”, percebe-se que este termo não contém o mesmo sentido de “desenvolvimento”. Crescimento econômico apresenta-se como um “componente” do desenvolvimento, ou seja, aquilo que entra na composição de alguma coisa. Neste caso, crescer não quer dizer desenvolver. Pelo contrário, desenvolver poderá conter aspectos de crescimento, mas como já vimos em outras passagens do mesmo discurso, neste momento, o sistema do capital, ao crescer, destrói e com isso, desenvolvimento sustentável toma um sentido próprio necessário ao nosso tempo de crise estrutural do capital.

O conceito de desenvolvimento sustentável transporta em sua conjugação a complexidade e a contraditoriedade dos problemas que ele tenta amenizar. Nestes termos, desenvolver sustentavelmente, seria aperfeiçoar e aprimorar o sistema produtivo e consumista do capital, contornando a destruição da vida humana e da natureza. Essa rearrumação de termos de crescimento para desenvolvimento sustentável, expressa não somente uma mudança de denominação, mas essencialmente, um deslocamento no projeto ideológico das agências do capital para os países avançados e em desenvolvimento. Na citação abaixo, podemos aferir tal problemática:

Devemos ter o cuidado extremo de considerar a pobreza como a causa do desenvolvimento não-sustentável, pois são os ricos que têm os maiores níveis de produção e consumo não-sustentáveis. Os ricos estão aptos a fazer escolhas, enquanto os pobres, presos em um círculo de privação e vulnerabilidade não podem fazê-lo. Enquanto os ricos podem adotar padrões de desenvolvimento sustentável e mostramse relutantes em fazê-lo, os pobres não têm alternativa além de fazer uso do seu entorno imediato. A pobreza está ligada à degradação ambiental, já que os pobres não têm outra escolha a não ser procurar e se beneficiar de recursos naturais escassos, como, por exemplo, usar madeira, como combustível, e água. Problemas de 
superconsumo e superdesenvolvimento são fatores-chave para a conservação e proteção ambiental e para a produção e o consumo sustentáveis. (UNESCO, 2005, p.29).

No discurso exposto, averigua-se (pelo menos nessa seqüência discursiva), que há uma delimitação precisa entre o mundo dos países avançados (industrializados), denominados de “ricos”, enquanto que do outro lado, encontram-se os países pobres. Isso demonstra e reforça a impossibilidade de alargamento e crescimento econômico industrial para os países pobres, pois a demarcação desse conceito de maneira precisamente binária, ou seja, rico ou pobre, nos sugere, que não há no momento, um estágio desenvolvimentista que propicie aos países pobres trilharem no objetivo de alcançarem os níveis de riqueza das nações industrializadas. Portanto, essa dicotomia deve existir infinitamente, pois, como podemos perceber, não é a pobreza a maior dificuldade para a sustentabilidade do planeta, mas o "superconsumo e superdesenvolvimento”, que como bem sabemos, não é encontrado em países que a desnutrição e outras simples doenças matam milhares de pessoas.

O projeto de desenvolvimento sustentável tem um vínculo essencialmente necessário com o ideal de globalização. A globalização apresenta-se para a ONU como a existência de um mercado global, harmonioso no qual todos poderão desfrutar das riquezas pluralmente produzidas. Nesta “aldeia Global”, cada um contribui com quanto e com o que pode. Cada país participa do sistema produtivo mundial colaborando de acordo com suas potencialidades e beneficiando-se harmoniosamente desse sistema. $\mathrm{O}$ problema do desenvolvimento econômico e da diminuição da pobreza no mundo não desenvolvido se configura num problema de gestão, ou seja, deve-se investir nos nichos de mercado que cada nação tem, potencializando esses recursos, integrando-os à rede mundial de mercado, da mesma forma que neste sistema global cada país participa de um modo economicamente específico. Identificamos nesse discurso um silenciamento, pois na medida em que o mercado global é concebido como um imenso supermercado, e que cada país representa um setor de oferta de mercadorias das mais diversas e necessárias à demanda dos mais variados clientes, apaga-se, com isso, os lugares ocupados pelos países subordinados e dependentes, como também, emudece-se o poder hierárquico e explorativo das nações subordinadoras presentes na totalidade desse sistema social. Relações entre países que se dão de maneira conflitiva, e não raras vezes, belicosamente, transmutam-se no projeto de sustentabilidade para a possibilidade da construção de um mundo pacífico e harmonioso. 


\section{A URGÊNCIA POR NOVOS VALORES SUSTENTÁVEIS À SOCIABILIDADE DO CAPITAL}

Ao lançarem as bases para a construção de um mundo sustentável, a ONU em conjunto com a UNESCO, definem o corpo de idéias e ações que deverão nortear as políticas econômicas, sociais e ambientais, que tanto as nações ricas como as pobres, respeitando suas especificidades, deverão inserir em seus projetos de desenvolvimento.

O conceito de sustentabilidade para a UNESCO (2005) pode ser traduzido nos seguintes termos:

\footnotetext{
Sustentabilidade refere-se às maneiras de se pensar o mundo e as formas de prática pessoal e social que levam a:

- Indivíduos com valores éticos, autônomos e realizados;

- Comunidades construídas em torno de compromissos coletivos, tolerância e igualdade;

- Sistemas sociais e instituições participativas, transparentes e justas, e

- Práticas ambientais que valorizem e sustentam a biodiversidade e os processos ecológicos de apoio à vida. (UNESCO, 2005, p. 30).
}

Na visão desse órgão internacional, deve-se pensar e agir diferentemente, para que o processo de sustentabilidade do homem e do planeta se inicie. Se observarmos a seqüência discursiva acima citada, perceberemos que a mudança se dá de maneira ascendente, ou seja, deve-se primeiramente transformar o indivíduo, em seguida, a comunidade; posteriormente, os sistemas e instituições sociais; e por último, o meio-ambiente. O indivíduo, desta maneira, converte-se no principal agente de mudança. Sem a sua inserção, os outros lugares sociais e o próprio meio-ambiente não poderão ser alterados para a dinâmica da sustentabilidade. Por esse motivo, a educação torna-se neste momento, o principal lugar de propagação ideológica desse projeto de desenvolvimento. Para demonstrar essa questão, recorreremos ao documento da UNESCO (2005):

A educação constitui o pilar central das estratégias para promover e enraizar os valores e comportamentos que o desenvolvimento sustentável exige. Como alguns pensadores assinalaram: "necessita-se de uma educação transformadora: uma educação que contribua a tornar realidade às mudanças fundamentais exigidas pelos desafios da sustentabilidade. Para acelerar o progresso em direção à sustentabilidade é necessário tornar as relações entre os seres humanos e o mundo natural mais calorosas e afetuosas, e buscar formas de desenvolvimento ambientais e sociais mais responsáveis”. A educação nos habilita como indivíduos e como comunidades a compreendermos a nós mesmos e aos outros e as nossas ligações com um meio ambiente social e natural de modo mais amplo. (UNESCO, 2005, p.43). 
A educação, nessa proposição, configura-se no "pilar” para tal projeto. Desta maneira, o termo exposto atribui como sentido para a atividade educativa o lugar de alicerce, no qual tem função central no enraizamento dos valores e comportamentos imprescindíveis para tal tarefa. Conforme a UNESCO (2005, p.43), a educação detém um papel-chave em "inspirar a crença que cada um de nós tem o poder e a responsabilidade de introduzir mudanças positivas em escala global”. Confirma-se a recorrência atribuída ao indivíduo, quanto a sua capacidade em operar mudanças no modo produtivo e consumista insustentável do capital da atualidade. Seu poder poderá transformar positivamente e globalmente a negatividade e destrutividade desse sistema. E a educação, como já explicitado, carrega em sua essencialidade a missão de embutir “valores, comportamentos e estilos de vida necessários para um futuro sustentável” (UNESCO, 2005, p.44).

As relações entre os indivíduos em todos os setores sociais, políticos e culturais devem, por esse cabedal de idéias, ser modificados e ressignificados em prol da paz, da justiça, da negociação, da igualdade, do respeito e da compreensão. Outros valores e comportamentos, de acordo com a ONU, fundados nos direitos humanos e no respeito à natureza, influirão diretamente numa transformação de um modelo de desenvolvimento destrutivo atual, para um outro que garanta a existência presente e futura sustentavelmente da humanidade.

Por esse intermédio, podemos inferir que o problema do desenvolvimento voltado à destruição da sociedade e do meio ambiente está fundado numa falta de consciência dos indivíduos em operarem relações consigo e com o mundo apoiados por valores sustentáveis.

\section{DA (IN)SUSTENTABILIDADE DO CONTROLE POLÍTICO DO CAPITAL A SUSTENTABILIDADE DO CONTROLE SOCIAL PARA ALÉM DESSE SISTEMA}

Ao expormos tal programa político-ideológico da ONU em campanha com a UNESCO de uma educação para a sustentabilidade do capital, lançamos uma luz sobre os motivos de tal tarefa histórica, suas intenções e propostas em relação a possibilidades de uma saída política para a humanidade. Crescer e destruir de acordo com a ONU é uma dinâmica de um modelo de desenvolvimento não mais saudável e possível em nossa época, mas por outro lado, desenvolver sustentavelmente, torna-se garantia de um presente e de um futuro à vida humana. Esse corpo de idéias defende que é possível impor uma lógica circular à dinâmica expansiva e acumulativa do capital, ou seja, pode-se infinitamente perpetuar as relações de 
produção e de consumo do mercado capitalista, bastando para isso, humanizar e harmonizar tal relação.

O capital, porém, configura-se numa forma de relação social produtiva voltada exclusivamente para o acúmulo e expansão de riqueza. Esta riqueza tem como fundamento social, a extração da mais-valia do trabalhador assalariado por parte do capitalista e a realização dessa riqueza em dinheiro no mercado consumidor. Com isso, a lógica desse sistema, por sua própria natureza e dinâmica, não pode e nem conhece outra direção e fim que não seja a obtenção e o entesouramento de uns poucos pela exploração de uma maioria trabalhadora. Essa lógica produtiva e reprodutiva sociometabólica tem como fim o valor de troca e não o valor de uso, ou seja, o valor de uso que seria o mesmo que a produção para as necessidades humanas transforma-se em meio para a compra e venda de tudo e de todos, até mesmo do próprio ser humano. Meszáros (2002) expõe de maneira esclarecedora tal questão:

O ter domina o ser em todas as esferas da vida. Ao mesmo tempo, o eu real dos sujeitos produtivos é destruído por meio da fragmentação e da degradação do trabalho à medida que eles são subjugados às exigências brutalizantes do processo de trabalho capitalista. (MESZÁROS, 2002, p.611).

Continuando, o mesmo autor realiza uma crítica radical na impossibilidade do controle político por meio de reformas desse sistema social, pois no capital "não há possibilidade de reforma que leve a transformações estruturais do modo de produção capiatlista (MÉSZÁROS, 2002, p.630). Assim, concordamos que, se a insustentabilidade do modo de produção capitalista encontra-se na base produtiva e reprodutiva da sociedade capitalista, apenas será possível a efetiva sustentabilidade da humanidade, numa outra forma radicalmente contrária a essa dinâmica social. Mészáros indica os fundamentos essenciais dessa outra ordem produtiva para além do capital:

Portanto, apenas a auto-realização por meio da riqueza (e não pela produção de riqueza alienante e reificada), como a finalidade da atividade-vital dos indivíduos sociais, pode oferecer uma alternativa viável à cega espontaneidade auto-reprodutiva do capital e suas conseqüências destrutivas (MESZÁROS, 2002, p.613).

O caminho para a extinção dessa ordem terá que ter como base fundante o trabalho livre e associado, no qual o trabalhador deterá o controle consciente da produção em todas as suas esferas; e as relações sociais terão como única finalidade as reais necessidade humanas.

Encontramos-nos, neste momento, portanto, numa encruzilhada, pois a alternativa entre socialismo ou barbárie se resume, nos dias de hoje, apenas a primeira alternativa. Já a segunda opção encontramo-la em todos os cantos do planeta, basta olharmos ao nosso redor. 


\section{REFERÊNCIAS}

ONU. Declaração do Milênio - Cimeira do Milênio. Nova Iorque, 2000.

ONU. Declaração do Milênio - Cimeira do Milênio. Nova Iorque, 6 - 8 de setembro de 2000. Apresenta textos sobre os Projetos da ONU. Disponível em: http://www.pnud.org.br. Acesso em: 10 jan. 2006.

UNESCO. Década da Educação das Nações Unidas para o Desenvolvimento Sustentável, 2005 - 2015: documento final do esquema internacional de implementação. Brasília, 2005.

UNESCO. Década da Educação das Nações Unidas para o Desenvolvimento Sustentável, 2005 - 2015: documento final do esquema internacional de implementação. Brasília, 2005. Apresenta textos sobre os Projetos da UNESCO. Disponível em: http://www.unesco.org.br. Acesso em: 10 jan. 2006.

FOLADORI, G. Limites do desenvolvimento sustentável. São Paulo: IMESP, 2001.

FOSTER. J. B. A ecologia de Marx: materialismo e natureza. Rio de Janeiro: Civilização Brasileira, 2005.

MÉSZÁROS, I. Para além do capital. São Paulo: Boitempo, 2002.

Produção destrutiva e estado capitalista. São Paulo: Ensaio, 1989.

LUCIANO ACCIOLY LEMOS MOREIRA

Graduado em História, especialista e mestre em educação brasileira e doutorando em análise do discurso - Todos na Universidade federal de Alagoas - UFAL Email: Luciano.almoreira@gmail.com 